\title{
Understanding the Behaviour of Olive Oil Tourists: A Cluster Analysis in Southern Spain
}

\author{
Juan Ignacio Pulido-Fernández ${ }^{1, *(1)}$, Jairo Casado-Montilla ${ }^{2}$ (D) and Isabel Carrillo-Hidalgo ${ }^{3}$ (i) \\ 1 Department of Economics, University of Jaén, 23071 Jaén, Spain \\ 2 Interuniversity Doctorate in Economic, Business and Legal Sciencies, University of Jaén, 23071 Jaén, Spain; \\ jcasado@ujaen.es \\ 3 Department of Accounting and Financial Economics, University of Jaén, 23071 Jaén, Spain; ihidalgo@ujaen.es \\ * Correspondence: jipulido@ujaen.es; Tel.: +34-95-321-2070
}

Received: 16 July 2020; Accepted: 19 August 2020; Published: 24 August 2020

\begin{abstract}
Olive oil tourism is a recent development in the countries of the Mediterranean basin, but it is now spreading to other regions of the world. The main reasons people are choosing this special interest tourism (SIT) are to find out about the culture surrounding olive oil and to enjoy the whole host of activities related to the product. This has led to the creation of strong links between olive oil tourism and other types of special interest tourism. The studies undertaken thus far to characterise the profile of olive oil tourism's demand, and its motivations, expectations and needs, have been limited and partial, focusing on specific cases. Therefore, this paper aims to take a closer look at the demand for olive oil tourism. Based on a survey of 609 visitors to olive oil mills in the south of Spain, olive oil tourists were segmented according to the type of trip and the olive oil tourism experience enjoyed during the trip, using a two-step cluster analysis. The results obtained enabled us to identify four segments with well-differentiated behaviours, which will help stakeholders, policy makers and destination managers to reach decisions, with a view to adapting their product to the expectations and needs of potential customers.
\end{abstract}

Keywords: olive oil tourism; special interest tourism; cluster analysis; olive oil tourist; Spain

\section{Introduction}

Olive oil tourism (hereinafter referred to as OOT) is an emerging type of tourism that has been gradually developing for just over a decade, mainly in rural areas where olives are the predominant crop [1]. These regions, located in countries such as Spain, Greece, Italy and Turkey, in the Mediterranean basin, and even in the United States, Argentina, Chile and Australia, are looking to diversify their main economic activity, the production of olive oil, toward the tourism sector.

The literature reviewed agrees that OOT is a special interest tourism (hereinafter, SIT), which derives from three types of general interest tourism (rural tourism, nature-based tourism and cultural tourism), which, in turn, shares aspects with other SIT, such as gastronomic, industrial, ethnographic, landscape, agro, creative, flora observation, wildlife observation, business and health tourism [2].

OOT provides an opportunity for tourists and visitors to learn all about the culture surrounding olive oil [3]. It also provides olive oil producers, as well as other companies associated with this agri-food activity, with the chance to position their brand and, above all, to increase the competitiveness of traditional olive growing, by reducing costs and increasing loyalty, and through incremental differentiation [4]. For these companies, OOT is certainly a collateral or complementary activity, but it can be very important in term of boosting their main activity-making an olive mill or olive 
growing estate more competitive-particularly by reducing the effects of seasonality, establishing entry barriers by means of singularization, and through establishing customer loyalty [5].

In fact, as we will see later, in the existing literature about this type of tourism, there are some studies that are interested in the demand for this type of tourism, seeking to ascertain information about demographic profiles, motivations and interests, albeit still in a very incipient way, due to the novelty of OOT [6].

These studies are still scarce, often presenting very limited statistical significance, and focusing on very specific cases, so that it is hard to generalise any findings. There is a need, therefore, to broaden existing knowledge about the demand for this type of tourism, in order to furnish stakeholders, policy makers and destination managers with sufficient information to help them make decisions with a view to adapting their product to the expectations and needs of potential customers.

Within this context, the main purpose of this paper is to examine in greater depth the profile of demand for OOT, as well as the main motivations, needs and interests of demand when it comes to this type of travel, especially with regard to characterising the olive oil tourism experience.

Once a deep literature review about OOT has been conducted, which will consider it an emerging tourism typology—a special interest tourism whose demand is not still fully portrayed-the proposed research hypothesis will be that it is possible to segment the demand for OOT into groups of tourists with different characteristics, allowing us to identify their main interests with regard to OOT and their knowledge of extra virgin olive oil, the motivations that led them to engage with this type of activity, their mode of travel and/or the means through which they booked different activities, and their assessment of these activities, among other variables.

These groups will allow us to sketch a more specific profile of consumers of OOT. Because it is an emerging form of tourism, the existing information lacks any analysis that goes further than simply describing the socio-demographic characteristics of the tourists or some of the interests that lead them to consume OOT. Thus, this paper may gain importance among tourism stakeholders in those territories where OOT has the potential to be developed. Furthermore, olive oil mill owners, who are thinking about diversifying their activities into tourism, will have a deeper knowledge about the different sort of tourists they want to draw to their OOT products, so a more accurate product can be developed in order to meet some specific needs and wants.

\section{Theoretical Framework}

This theoretical framework focuses on three key aspects that shape this paper. Firstly, a brief introduction is given to the concept of SIT and its importance today, as tourists' motivations are becoming increasingly broad and complex. Secondly, it presents OOT as an SIT in which demand is motivated by a desire to learn more about the olive oil culture, but also by other activities such as gastronomy, taking in the landscape, knowledge of flora and fauna, or creative activities. Finally, it devotes a subsection to analysing the contributions made so far by the scant literature dedicated to analysing the profile of OOT demand. The contributions made thus far are not only scarce, but also very focused on specific cases. However, in a paper dedicated to understanding the behaviour of olive oil tourists, it is necessary to analyse these previous studies.

\subsection{Special Interest Tourism}

SIT sparked interest among researchers during the last two decades of the 20th century, when the first publications appeared, dealing with topics such as business opportunities for companies in markets and the rapid evolution of the tourism industry toward an alternative based on consumer needs [7].

Currently, SIT continues to attract the attention of researchers due to changes in the way in which tourists plan their leisure time and, therefore, organise their travel in a more segmented way throughout the year, with more frequent but—at the same time-shorter stays [8]. This is the conditioning factor that explains the demand for more specific leisure activities, in order to fulfil needs based on the major interests of tourists. 
According to Brotherton and Himmetoğlu [9] (p. 15), people who seek these particularities when travelling in their free time start with the question "what interest/activity do I want to pursue, and where can 1 do it?"; hence, these potential tourists present certain special characteristics, such as a willingness to pay more, an allocentric character, and a desire to make their holiday an extension of their interests, compared to tourists who seek rest and relaxation, fun, or simply a break from their routine [10].

Meeting the needs of tourists and, above all, adapting in line with the changing trends in demand are some of the challenges facing tourist destinations and suppliers in this industry. Faced with this fact, Agarwal, Busby and Huang [11] (pp. 1-2) claim that:

The changing nature of such tourism demand has been more generally linked to the alleged shift from Fordism, characterised by mass production and economies of scale, to post-Fordism. The latter, in contrast, is consumption-led, and is based on economies of scope as consumers drive the production process so that their demand for more customised, tailor-made, differentiated products, may be catered for.

That is, it has to make the shift away from marketing medium-low level tourism products, oriented toward the supplier (commodities), towards a customer orientation with high value-added services that are complex, specialised and personalised, to meet the new needs of demand [12].

As we can see so far, SIT is a complex system in which demand and supply converge at a common point. It is determined primarily by the interests of demand, and is placed in the market by an increasingly specialised offer.

In light of this fact, Trauer [13] (p. 185) refers to the fact that:

SIT, it is suggested, should be viewed as part of a system, an interdisciplinary system, which comprises the overall environment (local to global), the tourist demand system, the tourism industry supply system with the media being conceptualized as a major influencer on tourism in the 21st century. It is the merging of all these components that make up SIT. The overall system is representative of political, economical, ecological, technological, and socio-economical and socio-cultural concerns, at local to global level.

Finally, it should be remembered that SIT represents a new way of consuming and producing tourism, to cope with increasingly exacting levels of demand and with more specific preferences, through a specialised offer that must be capable of meeting the needs of tourists in the 21st century.

\subsection{Olive Oil Tourism as a Special Interest Tourism}

OOT is a type of tourism that is developing in rural areas where olives are the predominant crop (mainly in the countries of the Mediterranean Basin: Spain, Italy, Greece, Morocco, Turkey and Portugal, although cases of OOT have also been found in countries such as Argentina, Australia, Chile, Japan, USA, and Lebanon).

As seen in the previous section, SIT is a complex system at the ends of which are, on the one hand, suppliers of a particular type of tourism, and, on the other hand, the demand for this type of tourism. According to Soleimani, Bruwer, Gross and Lee [14] (p. 2) "the advent of SIT has been an acknowledgment of the need in a postmodern consumer culture for recognition and provision of increasingly higher levels of customisation of tourism experiences", a fact that can be used to highlight the meeting point between both ends; that is, the destination in which SIT is generated.

This meeting point was defined by Hall and Weiler [15] through the addition of a geographical aspect, whereby potential tourists would seek to fulfil their interests when choosing which regions or destinations to visit. OOT, in response to these features, takes advantage of highly distinctive spaces-natural and rural as well as industrial spaces-to which demand is directed to consume the different activities designed and offered to meet the needs presented by demand in terms of the knowledge and enjoyment of the olive oil culture, which makes it SIT. 
In this case, OOT develops in territories that have olive crops, which are mainly rural areas where the economy is heavily dependent on agriculture and the production of olive oil. There is a rich culture and gastronomy that have developed around this agri-food product, which, according to de Salvo, Hernández-Mogollon, Di Climente and Calzati [16], favors the development of a territorial development strategy by leveraging all of these resources.

Therefore, participating in any activity linked to OOT involves travelling to a territory with very specific characteristics and with a prior motivation to experience the olive oil culture in person. These are normally the rural natural environments in which the mills that are beginning to set OOT in motion are located [17], and they represent one of the most attractive elements for tourists and visitors.

The existing literature has shown that OOT is a complex SIT. It stems from three types of general interest tourism (rural tourism, nature-based tourism and cultural tourism), but, at the same time, it is a type of tourism linked to a significant number of other SITs, including gastronomic tourism, and others such as industrial, ethnographic, landscape, agro, creative, flora observation, wildlife observation, business and health tourism.

Indeed, the implementation of OOT rests on the potential displayed by gastronomy in this type of tourism. Hence, many academic studies that characterise OOT highlight the importance of Protected Designations of Origin, Geographical Indicators and the gastronomic routes that revolve around this $[3,5,18-21]$.

Henderson [22] argues that many of the gastronomic activities carried out represent a special interest for tourists, and suggests that food in tourism is an important determining factor when choosing a destination. In addition, gastronomic tourism has been approached as an SIT that has different levels of interest depending on the tourists' motivations, and so there is a wide-ranging offer aimed at meeting their needs [23]. The gastronomic component of OOT represents one of its main attractions for demand, although not the only one, so the creation of products based on the tasting of olive oils, menus paired with oil, and even offering oil tasting sessions to tourists are some of the elements that are shaping this type of tourism.

It is possible to state that all components of OOT and the activities that shape this type of tourism, whether in a natural, rural or cultural environment, involve valuing and raising the status of available resources to meet the needs and motivations that are starting to emerge in current demand. These motivations, which are still in the process of identification, represent the origin of this tourist activity, which seems to be demanded, a priori, from visitors and tourists who want to learn more about the olive oil culture. In fact, OOT has already been defined as:
A leisure or business trip, requiring at least one overnight stay, and travellers are motivated by a set of activities based on olive oil and the local culture, heritage, landscape and customs that revolve around it. These components, combined, aim at fulfilling the very specific and diverse needs of this booming pastime, which will be met, on site, where the demanded activity is being developed and this will define the level of tourists' involvement in the production-consumption of this tourism typology. [24] (pp. 5-6)

\subsection{Literature Review about Olive Oil Tourism Demand}

As with the activities that shape this type of tourism, some of which have been discussed in the previous section to understand the specific interest that attracts visitors and tourists to OOT destinations, the literature, broadly speaking, lacks sufficient information and studies that fully characterise demand for olive oil tourism. Despite that, a literature review about OOT has already been carried out $[1,2]$. However, there have been some explorations of the ground [3,6,21,24-28] with a view to ascertaining the basic profile of this segment of tourists whose motivations appear, a priori, to be somewhat unclear and are very diverse.

According to the analyses conducted by Cañero et al. [6], López-Guzmán et al. [25] and Orgaz et al. [27] to characterise demand, the socio-demographic profile of olive oil tourists corresponds, mainly, to a person over the age of 60, retired, with a university education, with an income in excess of 
$€ 1500$, and mainly from Spain, followed by the French and the English. The main motivations that these authors demonstrated were a desire to know the geographic area, followed by learning about the world of olive oil, eating and drinking typical produce, and entertainment. In addition, it should be noted that olive oil tourists are regular consumers of olive oil on a daily basis.

Other studies yield similar results, taking as their sample all visitors or tourists drawn by companies that that are part of the gastronomic route encompassing Protected Designations of Origin in Andalusia [3] and olive oil Protected Designations of Origin-Baena, Lucena, Montoro-Adamuz and Priego de Córdoba [21]. In these cases, tourists are mostly over the age of 45, with a medium-high level of education, an income in excess of $€ 1001$, and are mostly from urban areas. Their motivations include visiting the oil mill and buying oil, and getting to know the region in which the olive oil tourism offer and the Protected Designation of Origin are located.

The similarities between the development of OOT and wine tourism, to which reference has been made in some studies [4], have led to comparisons being drawn between wine tourism and olive oil tourism. Millán and Pérez [28] argue that the organisation of the trip, the behaviour at the destination and the determining factors of their satisfaction bear great similarities, whereas expenditure at the destination and the level of purchasing power are greater in the case of the wine tourists, who are more willing to repeat the same activity than olive oil tourists.

Existing studies reveal that the duration of the trip in the case of olive oil tourism is less than $24 \mathrm{~h}$, which leads us to question whether, at the moment, this kind of activity can be classed as tourism, in the absence of an overnight stay [20,21]. In addition, knowledge of these resources and/or the desire to travel along an olive oil route are motivated by the recommendation of friends [27]. In turn, olive oil tourists are less likely to repeat their visit; these are facts that must be taken into account when creating and marketing olive oil tourism products.

In short, this type of tourism begins to outline the features of its demand: regular consumers of olive oil that show a great interest both in the olive oil production process and its properties, as well as the culture that surrounds it.

\section{Socioeconomic Importance of the Olive Oil Sector}

The olive oil sector is present in all five continents, spread over 58 countries. However, this product is consumed in 179 countries; therefore, to meet this high demand, 162,000 hectares of new olive groves are cultivated each year [29].

The production of olive oil is located particularly in countries in the Mediterranean Basin, where olive growing is at times the main source of income and livelihood for the various age-old cultures established throughout the Mediterranean. Table 1 shows the volume of olive oil production in tonnes for some of the countries developing olive oil tourism activities, compared to their consumption of olive oil.

As we can see, Spain produces approximately $50 \%$ of the total volume of olive oil in tonnes produced globally, followed by Italy and Greece, which have a total volume of approximately $7 \%$, in both cases, for the 2016/2017 campaign.

These countries, with very similar climates and cultures, have begun to develop OOT as a parallel activity to agriculture, which allows them to diversify this activity and generate additional sources of income that are extremely useful in years when production has declined, as we can see between the two campaigns presented. It should be noted, however, that countries such as the United States, Australia and Chile also have success stories in OOT, relying on this type of tourism to generate additional revenues to those obtained through the production of olive oil.

Furthermore, we must also take note of certain key data which indicate the dynamism that the olive oil sector generates in the global economy. In the opposite case, there are some countries whose level of olive oil production is well above consumption, so that a large part of production is intended for export, which is particularly the case with the United States. Table 2 shows some examples of how countries that do not produce olive oil, or where production volume is almost zero, show great interest 
in the consumption of olive oil and, year after year, have been increasing the amount of imported oil. In this case, we have chosen a time series to compare evolution between the campaigns of 2005-2006 and 2019-2020.

Table 1. Production and consumption of olive oil in tonnes per country $(\times 1000)$.

\begin{tabular}{ccccc}
\hline & \multicolumn{2}{c}{ Production } & \multicolumn{2}{c}{ Consumption } \\
\cline { 2 - 5 } Country & $\begin{array}{c}\mathbf{2 0 1 6 / 2 0 1 7} \\
\text { Campaign }\end{array}$ & $\begin{array}{c}\mathbf{2 0 1 7 / 2 0 1 8} \\
\text { Campaign }\end{array}$ & $\begin{array}{c}\mathbf{2 0 1 6 / 2 0 1 7} \\
\text { Campaign }\end{array}$ & $\begin{array}{c}\mathbf{2 0 1 7} / \mathbf{2 0 1 8} \\
\text { Campaign }\end{array}$ \\
\hline Spain & 1290.6 & 1262.2 & 454.4 & 478.1 \\
Greece & 195.0 & 346 & 105.0 & 130.0 \\
Italy & 182.3 & 428.9 & 438.9 & 580.0 \\
Morocco & 110.0 & 140 & 120.0 & 120.0 \\
Turkey & 208.0 & 263 & 150.0 & 176.5 \\
Portugal & 69.4 & 134.8 & 70.0 & 75.0 \\
Argentina & 24.0 & 45 & 7.5 & 8.0 \\
Australia & 21.0 & 21 & 45.0 & 48.0 \\
Chile & 19.0 & 22 & 6.0 & 7.5 \\
United States & 15.0 & 16 & 315.0 & 315.0 \\
Lebanon & 25.0 & 17 & 20.0 & 20 \\
Total for the group of countries proposed & 2159.3 & 2695.9 & 1731.8 & 1958.1 \\
World Total * & 2586.5 & 3379 & 2724.5 & 3039.0 \\
\hline
\end{tabular}

Source: [30]. * This figure is not the sum of the countries analyzed in Table 1.

Table 2. Imports in tonnes of olive oil per country $(\times 1000)$.

\begin{tabular}{ccc}
\hline Country & 2005/2006 Campaign & 2019/2020 Campaign \\
** \\
\hline United States & 250.0 & 315.0 \\
China & $12.0 *$ & 46.0 \\
Japan & 30.5 & 75.0 \\
Other non-producing countries & 25.0 & 85.0 \\
\hline
\end{tabular}

Source: [30]. * Figures for the 2008/2009 campaign. ${ }^{* *}$ Provisional data.

In short, the olive oil sector injects a great deal of dynamism into the global economy, and these data might partly reflect the interest in olive oil culture among non-producing countries, or those with very low production compared to the total world production.

\section{Characteristics of the Case Study}

The study presented in this paper was conducted in the Spanish regions of Andalusia and Extremadura. Both are situated in the south of Spain and have a total of 14 Protected Designations of Origin (DOP) for Extra Virgin Olive Oil. Of these 14 Protected Designations of Origin, 12 are located in Andalusia and two in Extremadura (Table 3).

The presence of these Protected Designations of Origin is a great support to the development of OOT, as pointed out above, and can become one of the conditioning factors that motivates businesses linked to these protected areas to move into the tourism industry, as analysed in some very specific cases focused on these regions $[5,18,20]$.

In addition, much of the land present in these regions is occupied by olive crops. Table 4 shows the olive crop area within each of these regions compared to the total number of hectares cultivated.

As shown in Table 4, the cultivation of olives has a significant weight in the total cultivated area. In Andalusia, olive groves account for the second largest cultivated or covered land area, after woodlands and forest, and in the case of Extremadura, it occupies fourth place.

Besides this, due to the close relationship between OOT and the rural environment, both regions Andalusia and Extremadura have great rural tourism infrastructures, such as the great availability of accommodation places and employment rates. Furthermore, they have the support 
of the public administration, which facilitates financial and organizational support to develop OOT programs (Table 5).

Table 3. Designations of Origin (DOP) for Extra Virgin Olive Oil in Andalusia and Extremadura.

\begin{tabular}{ccc}
\hline Self-Governing Region & Province & Designation of Origin \\
\hline & Cadiz & Sierra de Cádiz \\
\cline { 2 - 3 } Andalusia * & Córdoba & $\begin{array}{c}\text { Aceite de Lucena } \\
\text { Baena } \\
\text { Montoro-Adamuz } \\
\text { Priego de Córdoba }\end{array}$ \\
\cline { 2 - 3 } & Granada & $\begin{array}{c}\text { Montes de Granada } \\
\text { Poniente de Granada }\end{array}$ \\
\cline { 2 - 3 } & Jaén & $\begin{array}{c}\text { Sierra de Cazorla } \\
\text { Sierra Mágina } \\
\text { Sierra de Segura }\end{array}$ \\
\cline { 2 - 3 } & Málaga & Antequera \\
\cline { 2 - 3 } & Sevilla & Estepa \\
\hline \multirow{2}{*}{ Extremadura ${ }^{* *}$} & Cáceres & Gata-Hurdes \\
\cline { 2 - 3 } & Badajoz & Aceite Monterrubio \\
\hline & Source: ${ }^{*}[31], * *[32]$. &
\end{tabular}

Table 4. Olive crop area in hectares.

\begin{tabular}{cccc}
\hline Self-Governing Region & $\begin{array}{c}\text { Hectares of Olive } \\
\text { Groves }\end{array}$ & $\begin{array}{c}\text { Total Hectares } \\
\text { Cultivated/Covered }\end{array}$ & $\begin{array}{c}\text { \% of Total } \\
\text { Culivated/Covered Area }\end{array}$ \\
\hline Andalusia & $1,652,489$ & $3,540,903$ & $46.67 \%$ \\
Extremadura & 287,207 & $1,087,238$ & $26.41 \%$ \\
\hline
\end{tabular}

Source: [33].

Table 5. Tourism data related to rural tourism accommodations in 2019.

\begin{tabular}{ccccc}
\hline Region & $\begin{array}{c}\text { Rural } \\
\text { Travelers }\end{array}$ & $\begin{array}{c}\text { Number of } \\
\text { Overnights }\end{array}$ & $\begin{array}{c}\text { Average Rural Accommodation } \\
\text { Places per Month }\end{array}$ & $\begin{array}{c}\text { Average of Employed } \\
\text { Personnel }\end{array}$ \\
\hline Andalusia & 396,291 & $1,363,465$ & 20,485 & 3555 \\
Extremadura & 225,790 & 494,801 & 7590 & 1004 \\
\hline
\end{tabular}

Source: [34].

It should be noted that, despite the existence of other places in which OOT is in the process of development, these are the regions of Spain where this type of tourism possesses a greater weight. This fact is evidenced by the existing literature, which largely focuses on case studies located in these regions $[5,6,18,20,21,25-27,35,36]$, compared to those that have focused on Australia [37,38], Argentina [39], or Turkey [40,41].

\section{Methodology}

\subsection{Data Collection}

In order to gain a more in-depth understanding of OOT demand, we analysed data from 609 surveys conducted at different oil mills that offer olive oil tourism products and services in these two regions in the south of Spain, between January and December 2019. The technical specifications for the survey are provided in Table 6 . 
Table 6. Technical characteristics of the survey.

\begin{tabular}{cl}
\hline Population & Olive oil tourists (national and foreign) who visited the mills surveyed \\
Scope & Andalusia and Extremadura \\
Sampling points & 2 olive oil mills in Jaén, 1 in Córdoba, 1 in Seville, 1 in Badajoz and 1 in Cáceres \\
Type of survey & A structured questionnaire by means of a personal interview (annex 1) \\
Sample Size & 609 valid surveys \\
Sampling error & $4.0 \%$ \\
Level of confidence & 95 per cent $(p=\mathrm{q}=0.50)$ \\
Period of field work & January to December 2019 \\
\hline
\end{tabular}

To this end, given the impossibility of limiting the object of study (all olive oil tourists who visited these regions during the months in which the survey was conducted) and, therefore, since this is an infinite population, simple random sampling was applied, in which the only selection criterion was to have carried out olive oil tourism activities in the oil mills surveyed.

The survey was structured into six blocks. In the first of them, respondents were asked about different aspects of the trip and olive oil tourism experience they had participated in. In the second block, they were asked to rate the olive oil tourism proposal they took part in. The third block was dedicated to their assessment of the olive oil tourism destination. In the fourth block, they were asked about their level of spending on the day of the visit. The fifth block was dedicated to ascertaining the olive oil consumption habits of the respondents. Finally, the sixth block focused on analysing the sociodemographic characteristics of the respondents. Different types of questions were used: open-ended, closed (dichotomous and multichotomous, both single response and multiple choice) and mixed. Different types of scales were also used to measure the study variables: on the one hand, a Likert-type scale and, on the other, nominal non-metric scales, to identify the categories or options with which the behaviour of the interviewees can be identified, in the case of qualitative variables, which lack quantitative significance.

\subsection{Methodology}

The qualitative variables are described using frequencies and percentages, whereas quantitative variables are summarized in terms of their mean value and standard deviation.

The sample of respondents was analyzed with regard to the characteristics of the trip and the olive oil tourism experience. Question 15 of the questionnaire asked respondents to rate from 1 (minimum score) to 10 (highest score) a set of activities they participated in during their olive oil tourism experience. They were also asked to rate their experiences from different perspectives: leisure/entertainment, cuisine/gastronomy, commerce/business and education.

To analyse these data, the answers to this question were grouped into four dimensions pertaining to the perspective they were rating. It should be noted that not all of the respondents evaluated all of the activities, and so, in order to obtain a reliable measure with sufficient representation in the responses, we first analysed the internal consistency of the activities and, having verified that they had good consistency, we proceeded to obtain a weighted average based on the number of activities evaluated, as a global ratings measure of the activities selected by tourists. The weighted averages of the grades according to the responses are classified as follows: 0 in the case that the respondent did not respond to any of the activities, 1 if the grade assigned was a fail, 2 indicated a pass grade, 3 for good, and 4 for excellent.

Question 8 asked olive oil tourists about which elements attracted them most to this type of activity, in addition to their main reason for choosing OOT, asking them to score each element between 1 and 7 ( 1 being not at all attractive, 4 being indifferent, and 7 being highly attractive).

Having selected questions from that block of the survey, firstly, these variables were described, and, with the aim of segmenting tourists according to the type of trip and the olive oil tourism experience they participated in during their trip, a two-step cluster analysis was applied, as a valid tool in market segmentation when sociodemographic, behavior or geographic variables are analysed [42]. 
Cluster selection was based on the BIC criterion, considering a silhouette coefficient of more than 0.3 to determine the quality of the selected clusters. Subsequently, the results of the cluster were confirmed using a multinomial logistic regression model, finding correct cluster classification in $80 \%$ of cases, indicating the reliability and accuracy of the cluster solution to classify the olive oil tourists in relation to the type of trip and olive oil tourism experience, thus segmenting olive oil tourists into four groups.

Once the four clusters were generated, the sociodemographic characteristics of the tourists categorized in each of them were described, using frequencies and percentages in the case of categorical variables, and the mean value with its standard deviation in the case of continuous variables. Bivariate comparisons were made using the chi-square statistical test, in the case of categorical variables, and univariate multinomial logistic models to study the association of the variables with the segmentation cluster.

Statistical tests were carried out at a significance level of $5 \%$ using the statistical software package SPSS version 21.

\section{Results and Discussion}

The sociodemographic characteristics of the survey indicate that the average age of respondents is 39.69 , and the sample was split between $45.8 \%$ men and $54.2 \%$ women. $10.1 \%$ have no formal education or only primary education, $34 \%$ have a secondary level of education, $44.7 \%$ were university graduates and $11.2 \%$ have postgraduate studies (Master's Degree and/or PhD).

$66.2 \%$ of the respondents were employed, $25.6 \%$ were students or unemployed, and $8.2 \%$ were retired or homemakers. Regarding the employment category of olive oil tourists, $55.1 \%$ were skilled workers or middle management, $21.5 \%$ were business owners or independent professionals, $10.8 \%$ were civil servants with a university degree or teaching qualification, $6.3 \%$ were executives, and $6.3 \%$ were unskilled workers or civil servants without a qualification.

$17.7 \%$ of the respondents did not answer the question about their income level. Of those who answered this question, 21.6\% earned between 1200 and 1500 euros, $14.4 \%$ earned between 900 and $1200,13.2 \%$ earned between 1500 and 1800,13.2\% earned in excesses of 3000 euros, $19.2 \%$ earned between $1800-3000$, and $18.6 \%$ earned less than 900 euros.

Table 7 provides a description of the characteristics of the trip and the olive oil tourism experience, which was subsequently used to segment the population and create profiles of the tourists who engage in olive oil tourism experiences.

Table 8 describes the degree of attraction felt by tourists toward each of the aspects proposed in Table 9. An overall weighted average of the scores was obtained for the degree of attraction felt by tourists toward the different elements.

Table 9 shows, for each perspective (leisure/entertainment, cuisine/gastronomy, commerce/business, and education), the average weighted scores of the activities chosen by the respondents.

As explained in the methodology, with a silhouette measure of cohesion of 0.3 , four clusters were obtained, differing mainly in terms of the score obtained in the following variables: leisure/entertainment, cuisine/gastronomy, commerce/business, and education; their reasons for engaging in OOT; the aspects that interested them most during tastings (differentiating between oils with and without flaws, and differentiating between the varieties of EVOO); and the means by which they made their booking, and the type of stay.

The rest of the variables shown in the descriptive tables were irrelevant to the segmentation of olive oil tourists according to their choice of trip and olive oil tourism experience (the disclosure indicator was lower than $10 \%$ for the discrimination of the segments). The results, as pointed out previously, were four differentiated groups of olive oil tourists. Below is a characterisation of the clusters or groups in relation to their discriminant variables. 
Table 7. Description of the variables related to the characteristics of the trip and the olive oil tourism experience.

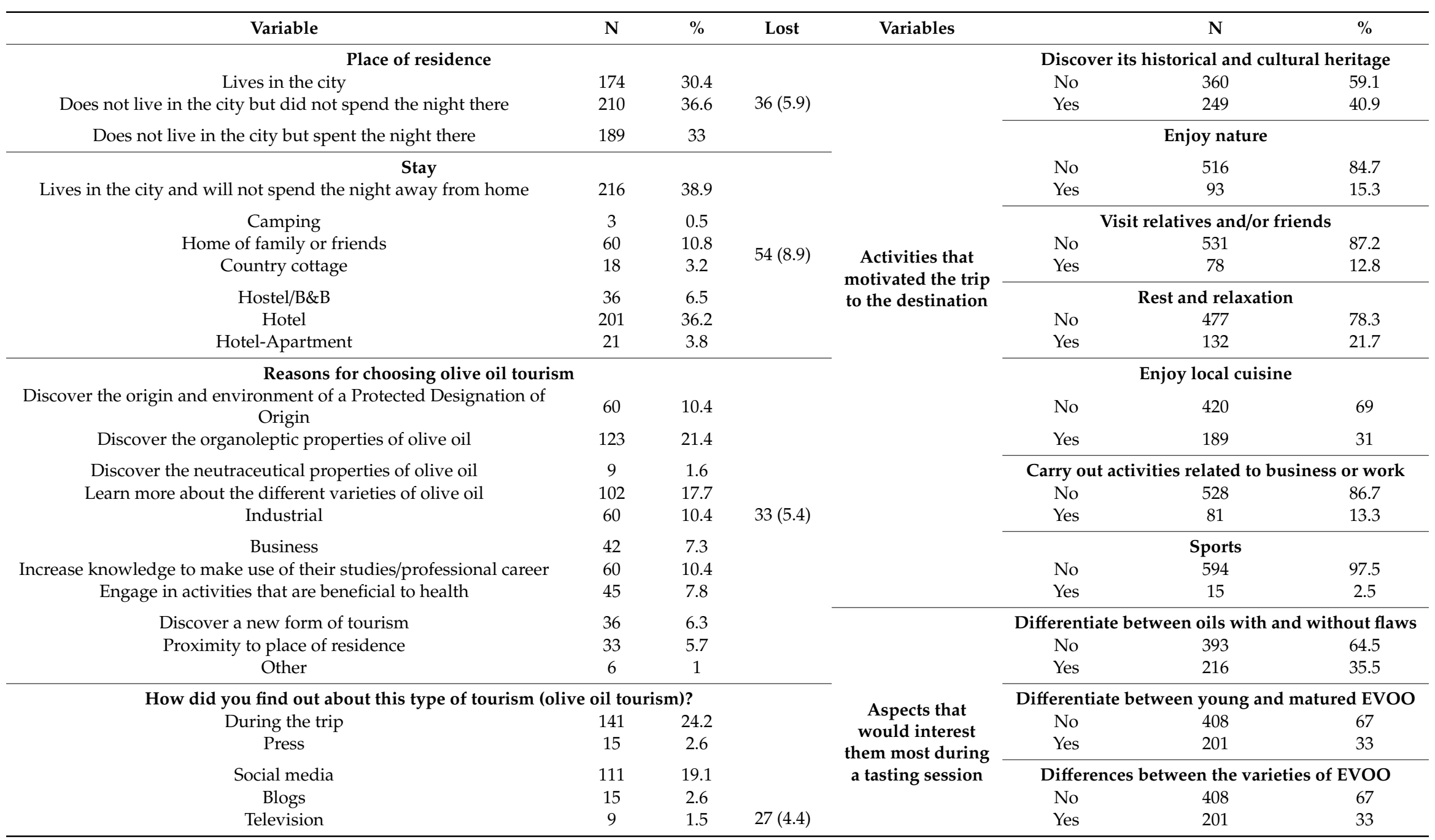


Table 7. Cont.

\begin{tabular}{|c|c|c|c|c|c|c|c|}
\hline Variable & $\mathbf{N}$ & $\%$ & Lost & Variables & & $\mathbf{N}$ & $\%$ \\
\hline Internet Ads & 9 & 1.5 & & & \multicolumn{3}{|c|}{$\begin{array}{l}\text { Pairing EVOO and the best ways to combine } \\
\text { them with different foods }\end{array}$} \\
\hline \multirow{2}{*}{$\begin{array}{c}\text { By consuming the brand of oil that this company produces } \\
\text { Through friends and family }\end{array}$} & 105 & 18 & & & No & 468 & 76.8 \\
\hline & 99 & 17 & & & Yes & 141 & 23.2 \\
\hline \multirow{2}{*}{$\begin{array}{l}\text { Other } \\
\text { University, classes, courses, studies }\end{array}$} & 30 & 5.2 & & \multirow{12}{*}{$\begin{array}{l}\text { Aspects you } \\
\text { found most } \\
\text { interesting when } \\
\text { tasting olive oils }\end{array}$} & \multicolumn{3}{|c|}{ Differentiate between oils with and without flaw: } \\
\hline & 48 & 8.2 & & & No & 366 & 60.1 \\
\hline \multicolumn{3}{|l|}{ Advance booking for activities } & \multirow{7}{*}{$30(4.9)$} & & Yes & 243 & 39.9 \\
\hline \multirow{3}{*}{$\begin{array}{l}\text { More than a month } \\
\text { Between three weeks and a month } \\
\text { Between two and three weeks }\end{array}$} & \multirow{2}{*}{$\begin{array}{c}213 \\
39\end{array}$} & \multirow{2}{*}{$\begin{array}{c}36.8 \\
6.7\end{array}$} & & & \multicolumn{3}{|c|}{ Differentiate between young and matured EVOO } \\
\hline & & & & & No & \multirow{2}{*}{$\begin{array}{l}477 \\
132\end{array}$} & 78.3 \\
\hline & 45 & 7.8 & & & Yes & & 21.7 \\
\hline \multirow{3}{*}{$\begin{array}{l}\text { Between one and two weeks } \\
\text { Less than a week. } \\
\text { On the day of the activity itself }\end{array}$} & 66 & 11.4 & & & \multicolumn{3}{|c|}{ Differences between the varieties of EVOO } \\
\hline & 111 & 19.2 & & & No & 414 & 68 \\
\hline & 105 & 18.1 & & & Yes & 195 & 32 \\
\hline \multicolumn{2}{|l|}{ Methods for booking activities } & & \multirow{9}{*}{$42(6.9)$} & & \multicolumn{3}{|c|}{$\begin{array}{l}\text { Pairing EVOO and the best ways to combine } \\
\text { them with different foods }\end{array}$} \\
\hline Online form on the company's website & 108 & 19 & & & No & 525 & 86.2 \\
\hline Traditional travel agency & 60 & 10.6 & & & Yes & 84 & 13.8 \\
\hline Online travel agency & 30 & 5.3 & & \multirow{12}{*}{$\begin{array}{l}\text { Type of tourism } \\
\text { or activities } \\
\text { carried out over } \\
\text { the last } 12 \text { months }\end{array}$} & & e tou & \\
\hline Telephone & 129 & 22.8 & & & No & 453 & 74.4 \\
\hline Directly with the company, before the activity itself & 174 & 30.7 & & & Yes & 156 & 25.6 \\
\hline Other & 9 & 1.6 & & & & omic & \\
\hline Friends, acquaintances & 6 & 1.1 & & & No & 396 & 65 \\
\hline Work, University & 51 & 9 & & & Yes & 213 & 35 \\
\hline \multicolumn{4}{|c|}{ Increased knowledge about harvesting, extraction and production } & & \multicolumn{3}{|c|}{ Industrial tourism } \\
\hline No & 6 & 1 & \multirow{2}{*}{$18(3)$} & & No & 540 & 88.7 \\
\hline Yes & 585 & 99 & & & Yes & 69 & 11.3 \\
\hline \multicolumn{3}{|c|}{ Interest in other olive oil tourism proposals } & & & & re tou & \\
\hline No & 60 & 10.2 & \multirow{2}{*}{$21(3.4)$} & & No & 495 & 81.3 \\
\hline Yes & 528 & 89.8 & & & Yes & 114 & 18.7 \\
\hline
\end{tabular}


Table 7. Cont.

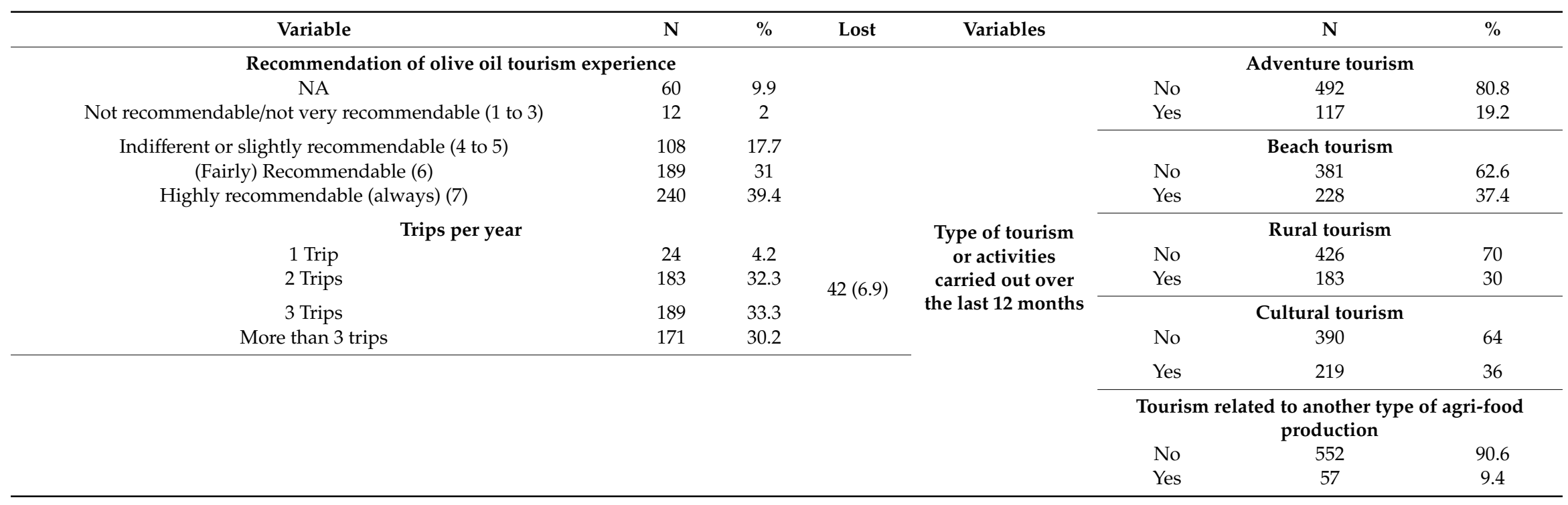


Table 8. Description of the aspects that make up the olive oil tourism experience, and the overall score obtained with Cronbach's alpha test.

\begin{tabular}{|c|c|c|c|c|c|c|}
\hline \multicolumn{7}{|c|}{ Attractiveness of the Different Elements of the Olive Oil Tourism Activities } \\
\hline Tasting & $\mathrm{N}$ & $\%$ & Museums and interpretation centres & $\mathrm{N}$ & $\%$ & \\
\hline NA & 150 & 24.6 & NA & 261 & 42.9 & \\
\hline Not at all to not very attractive (1-3) & 12 & 2 & Not at all to not very attractive (1-3) & 96 & 15.8 & \\
\hline Attractive or very attractive (6-7) & 405 & 66.5 & Attractive or very attractive (6-7) & 150 & 24.6 & \\
\hline \multicolumn{3}{|c|}{ Tastings and food pairing together with other local products } & \multicolumn{4}{|c|}{ Culture and history of olive oil } \\
\hline NA & 243 & 39.9 & NA & 240 & 39.4 & \\
\hline Not at all to not very attractive (1-3) & 15 & 2.5 & Not at all to not very attractive (1-3) & 60 & 9.9 & \\
\hline Indifferent-somewhat attractive (4-5) & 36 & 5.9 & Indifferent-somewhat attractive (4-5) & 84 & 13.8 & \\
\hline Attractive or very attractive (6-7) & 315 & 51.7 & Attractive or very attractive (6-7) & 225 & 36.9 & \\
\hline \multicolumn{3}{|c|}{ Routes around the olive grove } & \multicolumn{4}{|c|}{ Enjoying spas and beauty and/or health treatments } \\
\hline NA & 225 & 36.9 & NA & 306 & 50.3 & \\
\hline Not at all to not very attractive (1-3) & 51 & 8.4 & Not at all to not very attractive (1-3) & 84 & 13.8 & \\
\hline Indifferent-somewhat attractive (4-5) & 129 & 21.2 & Indifferent-somewhat attractive (4-5) & 33 & 5.4 & \\
\hline Attractive or very attractive (6-7) & 204 & 33.5 & Attractive or very attractive (6-7) & 186 & 30.5 & \\
\hline \multicolumn{3}{|c|}{ Contact with the processes of harvesting and production } & \multicolumn{3}{|c|}{ Overall Score for the attractiveness of the elements of the activity } & Cronbach's Alpha \\
\hline NA & 222 & 36.5 & NA & 123 & 20.2 & \multirow{3}{*}{0.9} \\
\hline Indifferent-somewhat attractive (4-5) & 93 & 15.3 & Indifferent-somewhat attractive & 264 & 43.3 & \\
\hline Attractive or very attractive (6-7) & 240 & 39.4 & Attractive or very attractive & 195 & 32 & \\
\hline
\end{tabular}


Table 9. Grades awarded to the activities carried out by olive oil tourists in terms of leisure, gastronomy, commerce and education.

\begin{tabular}{|c|c|c|c|c|c|c|c|}
\hline $\begin{array}{l}\text { Grade Awarded to Activities from the } \\
\text { Perspective of Leisure/Entertainment }\end{array}$ & $\mathbf{N}$ & $\%$ & Cronbach's Alpha & $\begin{array}{l}\text { Grade Awarded to Activities from the } \\
\text { Perspective of Commerce/Business }\end{array}$ & $\mathbf{N}$ & $\%$ & Cronbach's Alpha \\
\hline NA & 165 & 27.1 & \multirow{5}{*}{0.749} & NA & 384 & 63.1 & \multirow{5}{*}{0.84} \\
\hline Fail & 15 & 2.5 & & Fail & 36 & 5.9 & \\
\hline Pass & 27 & 4.4 & & Pass & 18 & 3 & \\
\hline Good & 165 & 27.1 & & Good & 72 & 11.8 & \\
\hline Excellent & 237 & 38.9 & & Excellent & 99 & 16.3 & \\
\hline $\begin{array}{l}\text { Grade Awarded to Activities from the } \\
\text { Perspective of Gastronomy/Cuisine }\end{array}$ & $\mathbf{N}$ & $\%$ & Cronbach's Alpha & $\begin{array}{l}\text { Grade Awarded to Activities from the } \\
\text { Perspective of Education }\end{array}$ & $\mathbf{N}$ & $\%$ & Cronbach's Alpha \\
\hline NA & 306 & 50.2 & \multirow{5}{*}{0.812} & NA & 342 & 56.2 & \multirow{5}{*}{0.832} \\
\hline Fail & 12 & 2 & & Fail & 21 & 3.4 & \\
\hline Pass & 24 & 3.9 & & Pass & 33 & 5.4 & \\
\hline Good & 102 & 16.7 & & Good & 93 & 15.3 & \\
\hline Excellent & 165 & 27.1 & & Excellent & 120 & 19.7 & \\
\hline
\end{tabular}




\subsection{Cluster 1-Dabbler Olive Oil Tourists}

This cluster contained a total of 165 respondents, $47.3 \%$ of which reside in the city. In general, this cluster is characterised by the fact that, for the most part, these tourists reside in the city or do not spend the night away from home (56.4\%), and of the other half, $23.6 \%$ stayed in a hotel, $14.5 \%$ with friends and family, and the rest in hostels/B\&Bs and apartments (approximately $5 \%$ ). With regard to the main reason for choosing OOT, this group is characterised by wanting to know more about the differences between varieties of olive oil (21.8\%), engaging in activities that are beneficial to their health $(21.8 \%)$, and choosing olive oil tourism on account of the proximity of this experience to their place of residence (18.2\%). Bookings were mainly made using an online form on the company's website $(30.9 \%)$, by telephone $(20 \%)$, or directly with the company before the activity itself $(27.3 \%)$. In total, $65.5 \%$ indicated that the difference between the varieties of oil was the aspect that interested them most. In relation to the ratings given to the activities in terms of leisure, $50.9 \%$ did not rate any of them as leisure or fun, $36 \%$ rated them as being excellent and $12.7 \%$ good. In terms of gastronomy, $85.5 \%$ did not respond or rate the activities, and the remainder rated the activities as excellent $(9.1 \%)$ and good (3.6\%). All of the participants in this group did not rate the activities in terms of commerce/business or education.

\subsection{Cluster 2-Experiential Olive Oil Tourists}

This cluster contained a total of 108 respondents, $36 \%$ of which reside in the city. $55 \%$ spent the night away from home, staying mainly in hotels $(25 \%)$ and hostels/B\&Bs $(19.4 \%)$, and only $5.6 \%$ with family or friends. The main reasons that led them to choose OOT included learning more about the varieties of olive oil (25\%), increasing knowledge to make better use of their studies/career $(19.4 \%)$, business $(16.7 \%)$, and discovering a new form of tourism $(13.9 \%)$. They made their reservations through work/university (30.6\%), 13.9\% filled in an online form or booked the activity directly with the company, and $11.1 \%$ booked by telephone or using an online travel agency. The majority of the olive oil tourists in this group $(63.9 \%$ ) had previously taken beach holidays. In total, $75 \%$ of the members of this group rated the activities with regard to leisure and fun as either good or excellent, $13.9 \%$ gave a pass grade, $8.3 \%$ awarded a fail grade, and $2.8 \%$ did not rate them as leisure activities. In total, $66.7 \%$ rated the activities in terms of gastronomy with a good grade, followed by $16.7 \%$ that awarded a pass grade. Only $5.6 \%$ of tourists in this group felt that these activities could not be rated in terms of gastronomy. In total, $50 \%$ rated the activities in terms of commerce/business with a good grade, $13.9 \%$ awarded a pass grade and $16.7 \%$ awarded a fail grade. In terms of education, $5.3 \%$ rated the activities as good, and $25 \%$ awarded a pass grade. In total, $11.1 \%$ awarded the activities a fail grade in terms of education, and only $5.6 \%$ rated them excellent.

\subsection{Cluster 3-Half-Day Guest Olive Oil Tourists}

With a total of 126 participants, $66.7 \%$ of which do not reside and did not spend the night in the city, this group is characterised by a large majority of participants who spent the night away from home $(72 \%)$, staying mostly in hotels $(38 \%)$ and with relatives and friends $(21.4 \%)$. The main reasons for choosing OOT included discovering the origin and the environment of a Protected Designation of Origin $(21.4 \%)$, learning about the organoleptic properties of olive oil $(21.4 \%)$, increasing their knowledge to make better use of their studies/career (10\%), and $11 \%$ for industrial reasons. Reservations were made $(50 \%)$ directly with the company just before the activity, $19 \%$ by telephone and $16.7 \%$ using an online form. $54.8 \%$ indicated that what most interested them in the tasting sessions was learning how to differentiate between oils with and without flaws. In total, $71.4 \%$ had not been on a beach holiday in the previous year. All of the participants rated the activities as leisure, with $85.7 \%$ awarding an excellent grade and $14.3 \%$ awarding a good grade. In total, $88.1 \%$ of the tourists rated the activities in terms of gastronomy with an excellent grade, and $9.5 \%$ did not rate the activities in gastronomic terms. In total, $61.9 \%$ rated the activities as excellent on a commercial level, and $31 \%$ did not assign any commercial or business value. In total, $66.7 \%$ of the respondents rated the activities as excellent in 
terms of education, and $9.5 \%$ assigned a good grade. However, $23.8 \%$ of participants in this group did not rate any of the activities as educational.

\subsection{Cluster 4-Enthusiast Olive Oil Tourists}

This cluster contained a total of 78 participants, $70 \%$ of which do not reside but did spend the night in the city, mostly in hotels (84.6\%), and 7.7\% in hotel-apartments. Most of the participants indicated that their main reason was to learn about the organoleptic properties of olive oil $(69.2 \%)$, followed by discovering the origin and environment of a Protected Designation of Origin $(11.5 \%)$. Reservations were made mostly by phone $(73.1 \%)$, with $15.4 \%$ making the booking directly with the company just before the activity. With regard to tasting sessions, $96.2 \%$ indicated that the aspect that interested them the most was learning to differentiate between oils with and without flaws. In total, $92.3 \%$ had not been on a beach holiday in the previous year. When rating the activities in terms of leisure and entertainment, $38.5 \%$ awarded them a good grade, and $34.6 \%$ awarded an excellent grade. The rest of the participants did not rate the activities in terms of leisure and fun. None of participants in this group rated the activities in terms of gastronomy or commerce/business, and $96.2 \%$ did not rate them as an educational activity.

The analysis of the clusters according to the sociodemographic variables (Table 10) shows that there are no significant differences in the clusters according to gender $(p=0.243)$, with a similar distribution of men and women in the different clusters. However, significant differences were observed between the clusters regarding the average age of the respondents. Wald's chi-square statistical test of the univariate multinomial model indicates a significant association between age and the segmentation cluster (Wald $=17.94$, D.F. $1 ; p<0.001)$. Older tourists (48 years of age $(\mathrm{SD}=9.81)$ and $\mathrm{N}=69$ ) are more likely to be classified in cluster 4 , followed by cluster $3(42.2$ years of age $(\mathrm{SD}=11.9)$ and $\mathrm{N}=123)$, cluster 1 ( 40.4 years of age $(\mathrm{SD}=12.4)$ and $\mathrm{N}=138)$ and cluster 2 , where the younger participants are classified $(28.8$ years of age $(\mathrm{SD}=11.9)$ and $\mathrm{N}=84)$.

With regard to the level of education, significant differences are observed, and we are more likely to find a respondent without a formal education or with only a primary education in cluster $1(71 \%$ of tourists without a formal education are classified in cluster 1), whereas a higher percentage of tourists with postgraduate studies are classified in cluster $3(57.9 \%$ of graduate students are characterised by being in cluster 3$)(p<0.001)$.

Unemployed respondents or students are classified, for the most part, in cluster $2(57.9 \%)$, in contrast to $12.4 \%$ of the employed respondents classified in this cluster. The lowest percentage of unemployed respondents or students are classified in cluster 4, and students and the unemployed are less likely to have a profile defined in cluster 4 in terms of olive oil tourism experience. Cluster 1 presents the lowest level of tourist differentiation according to their occupation, and there is greater homogeneity in the percentages of unemployed, employed or retired tourists classified in cluster 1.

In relation to professional category, the majority of civil servants with a qualification and a high percentage of executives are classified in cluster 1, giving this cluster a more defined profile with regard to the olive oil tourism experience. The majority of independent professionals and business owners are classified in cluster 3. However, the majority of unskilled workers are classified in cluster 2 . Thus, according to occupational category, there is a significantly higher or lower probability of belonging to a cluster $(p<0.001)$.

Finally, in relation to income, lower income respondents are mainly classified in cluster $2(54.2 \%)$, while those on higher incomes are classified in clusters 1 and $3(p<0.001)$.

It should be noted that the clusters do not contain all of the people surveyed, since the aim was to generate very homogeneous groups that respond to statistically significant characteristics, and this causes the segments obtained to yield a very specific profile in each case.

In relation to consumption habits, $97 \%$ of respondents answered the question regarding the frequency with which they consume olive oil. In total, $76 \%$ consume it daily, $13.7 \%$ consume it between 
4 and 6 days a week, $6.6 \%$ consume it between 1 and 3 days a week, and $3.6 \%$ did not consume it. In total, $86.2 \%$ of respondents stated that they consume the oil raw, and $74.4 \%$ cooked.

Table 10. Distribution of respondents per cluster according to sociodemographic variables.

\begin{tabular}{|c|c|c|c|c|c|c|}
\hline \multicolumn{2}{|l|}{ Characteristic Cluster of the Olive Oil Tourism Experience } & \multirow{2}{*}{$\begin{array}{r}\text { Cluster } 1 \\
\text { Gender }\end{array}$} & \multirow[t]{2}{*}{ Cluster 2} & \multirow[t]{2}{*}{ Cluster 3} & \multirow[t]{2}{*}{ Cluster 4} & \multirow[t]{2}{*}{ Chi-Square Test } \\
\hline & & & & & & \\
\hline Male & $\mathrm{N}$ & 51 & 39 & 63 & 24 & \multirow{3}{*}{$\begin{array}{l}\text { Chi-square }(3)=4.18 \\
\quad p \text {-value }=0.243\end{array}$} \\
\hline \multirow[t]{2}{*}{ Female } & $\mathrm{N}$ & 75 & 54 & 57 & 27 & \\
\hline & $\%$ & $35.2 \%$ & $25.4 \%$ & $26.8 \%$ & $12.7 \%$ & \\
\hline \multicolumn{7}{|c|}{ Education } \\
\hline No education or primary Ed. & $\%$ & $71.4 \%$ & $7.1 \%$ & $0.0 \%$ & $21.4 \%$ & \multirow{5}{*}{$\begin{array}{c}\text { Chi-square }(9)=99.575 \\
p \text {-value }=0\end{array}$} \\
\hline \multirow[t]{2}{*}{ Secondary/High School/Middle School Ed. } & $\mathrm{N}$ & 33 & 30 & 33 & 45 & \\
\hline & $\%$ & $23.4 \%$ & $21.3 \%$ & $23.4 \%$ & $31.9 \%$ & \\
\hline \multirow[t]{2}{*}{ Graduate } & $\mathrm{N}$ & 69 & 60 & 54 & 21 & \\
\hline & $\%$ & $33.8 \%$ & $29.4 \%$ & $26.5 \%$ & $10.3 \%$ & \\
\hline \multirow[t]{2}{*}{ Student or Unemployed } & $\mathrm{N}$ & 33 & 66 & 12 & 3 & \multirow{6}{*}{$\begin{aligned} \text { Chi-square }(6) & =120.963 \\
p \text {-value } & =0\end{aligned}$} \\
\hline & $\%$ & $28.9 \%$ & $57.9 \%$ & $10.5 \%$ & $2.6 \%$ & \\
\hline \multirow[t]{2}{*}{ Employed } & $\mathrm{N}$ & 114 & 39 & 93 & 69 & \\
\hline & $\%$ & $36.2 \%$ & $12.4 \%$ & $29.5 \%$ & $21.9 \%$ & \\
\hline \multirow[t]{2}{*}{ Retired/Homemaker } & $\mathrm{N}$ & 12 & 0 & 15 & 6 & \\
\hline & $\%$ & $36.4 \%$ & $0.0 \%$ & $45.5 \%$ & $18.2 \%$ & \\
\hline \multicolumn{7}{|c|}{ Category } \\
\hline \multirow[t]{2}{*}{ Unskilled worker or Civil Servant without a qualification } & $\mathrm{N}$ & 9 & 12 & 3 & 0 & \\
\hline & $\%$ & $37.5 \%$ & $50.0 \%$ & $12.5 \%$ & $0.0 \%$ & \\
\hline Skilled worker or middle management & $\mathrm{N}$ & 60 & 48 & 39 & 60 & \\
\hline & & Income & & & & \\
\hline$<900$ & $\mathrm{~N}$ & 21 & 39 & 9 & 3 & \\
\hline & $\%$ & $29.2 \%$ & $54.2 \%$ & $12.5 \%$ & $4.2 \%$ & \\
\hline $900-1200$ & $\mathrm{~N}$ & 18 & 15 & 9 & 12 & \\
\hline & $\%$ & $33.3 \%$ & $27.8 \%$ & $16.7 \%$ & $22.2 \%$ & \\
\hline $1200-1500$ & $\mathrm{~N}$ & 42 & 12 & 12 & 27 & Chi-square $(15)=116.671$ \\
\hline & $\%$ & $45.2 \%$ & $12.9 \%$ & $12.9 \%$ & $29.0 \%$ & $p$-value $=0$ \\
\hline $1500-1800$ & $\mathrm{~N}$ & 15 & 0 & 15 & 9 & \\
\hline & $\%$ & $38.5 \%$ & $0.0 \%$ & $38.5 \%$ & $23.1 \%$ & \\
\hline $1800-3000$ & $\mathrm{~N}$ & 27 & 12 & 36 & 15 & \\
\hline & $\%$ & $30.0 \%$ & $13.3 \%$ & $40.0 \%$ & $16.7 \%$ & \\
\hline$>3000$ & $\mathrm{~N}$ & 30 & 6 & 21 & 0 & \\
\hline & $\%$ & $52.6 \%$ & $10.5 \%$ & $36.8 \%$ & $0.0 \%$ & \\
\hline
\end{tabular}

Analysis of the segmentation of tourists according to their consumption habits indicates that those who do not consume oil (100\% of these) are classified in cluster 2 , in contrast to those who consume it 1 to 3 days a week $(88.9 \%$ ), who are associated with cluster 3 (chi-square significant association $=99$; $d$. $f=9$; $p$-value $<0.001)$. Consumers of cooked oil are more likely to be classified in cluster 1 , while those who consume raw oil are found in greater percentages in clusters 3 and $4(p<0.001)$. 


\section{Conclusions}

The results presented in this article have made it possible to validate the initial hypothesis proposed. Through the data obtained based on the design of a complex survey with more than 35 questions, it was possible to segment olive oil tourists into different groups regarding their motivations, interests, mode of booking, type of traveller (tourist or day-tripper), type of accommodation chosen and, finally, a quadruple assessment of each of the activities carried out on the basis of the four proposed perceptions (leisure, gastronomy, business, and education), according to the results obtained.

There is a need to clarify from the outset that, although we talk here of OOT, many respondents were not tourists, but rather visitors, since they did not spend the night away from home. However, since it is an emerging type of tourism, given the limited number of tourists driven by these motivations and the need to characterise the demand for this type of activity, we preferred to analyse all those surveyed, even though not all of them were tourists. In fact, this is reflected in the segmentation applied.

Before the information was processed, OOT was shown to possess a number of features that situate it within the category of SIT, and some very specific motivations lead tourists to choose activities relating to olive oil, involving, on many occasions, a high degree of involvement on their part. Furthermore, to avoid redundancy when characterising the demand for OOT, we analysed the existing literature and studies that have created random surveys administered to olive oil tourists that have provided a primary profile.

The characterisation provided here allows demand to be classified into several groups. The differences displayed by these four clusters reside mainly in the form of travel (whether or not they stay overnight, and if they do where they stay), along with the interests that motivate them to choose OOT, which take on a more professional and/or specialised focus (learning to differentiate between different varieties of EVOO, or to identify flaws in tasting sessions) among segments of olive oil tourists with a higher level of education, or those seeking professional and/or academic benefit by carrying out these activities (Table 11).

Table 11. Olive oil tourists' characteristics.

\begin{tabular}{|c|c|}
\hline Olive Oil Tourist Clusters & Olive Oil Tourists' Main Characteristics \\
\hline $\begin{array}{c}\text { Cluster } 1 \text {-Dabbler Olive } \\
\text { Oil Tourists }\end{array}$ & $\begin{array}{l}\text { - Origin: Mainly residents or visitors who do not overnight in the city. } \\
\text { - Accommodation: Non-residents who overnight prefer hotels and relatives } \\
\text { and friends' houses. } \\
\text { - Wants: Improving their knowledge about varieties of olive oil and looking } \\
\text { for activities beneficial to their health. } \\
\text { - Booking: Mainly online or directly in the company. }\end{array}$ \\
\hline $\begin{array}{l}\text { Cluster 2-Experiential } \\
\text { Olive Oil Tourists }\end{array}$ & $\begin{array}{l}\text { - } \quad \text { Origin: Non-residents. Half of them overnight in another city. } \\
\text { - } \quad \text { Accommodation: Hotels and hostels. } \\
\text { - Wants: Improving their knowledge about varieties of olive oil and } \\
\text { increasing knowledge to make better use of their studies/career. } \\
\text { - Booking: Through workplace and online. }\end{array}$ \\
\hline $\begin{array}{c}\text { Cluster 3-Half-Day Guest } \\
\text { Olive Oil Tourists }\end{array}$ & $\begin{array}{l}\text { - } \quad \text { Origin: Non-residents who overnight in another city. } \\
\text { - } \quad \text { Accommodation: Hotels or relatives and friends' houses. } \\
\text { - Wants: discovering the origin and the environment of a Protected } \\
\text { Designation of Origin and learning about the organoleptic properties of } \\
\text { olive oil. } \\
\text { - Booking: Immediately in the company. }\end{array}$ \\
\hline $\begin{array}{c}\text { Cluster 4-Enthusiast Olive } \\
\text { Oil Tourists }\end{array}$ & $\begin{array}{l}\text { - } \quad \text { Origin: Non-residents who overnight in the city. } \\
\text { - } \quad \text { Accommodation: Mainly hotels. } \\
\text { - } \quad \text { Wants: A majority prefer learning about the organoleptic properties of } \\
\text { olive oil. } \\
\text { - } \quad \text { Booking: A majority made the reservation by phone. }\end{array}$ \\
\hline
\end{tabular}

The results obtained are very useful for companies that are currently developing OOT, or for those thinking of diversifying their economic activity; they are also useful for policymakers and destination 
managers, who have to guide their decisions according to the motivations and expectations of the real or potential demand. Finally, we must highlight the need to replicate these analyses regarding demand for OOT as it increases its market volume in the different geographical points where it is located, in order to obtain an increasingly accurate profile for the clusters obtained in this study.

Author Contributions: Conceptualization, J.C.-M. and I.C.-H.; methodology, J.I.P.-F.; software, J.I.P.-F.; validation, J.I.P.-F., J.C.-M. and I.C.-H.; formal analysis, I.C.-H.; investigation, J.C.-M.; resources, J.I.P.-F.; data curation, J.I.P.-F.; writing — original draft preparation, J.C.-M.; writing—review and editing, I.C.-H.; visualization, J.C.-M.; supervision, J.I.P.-F.; project administration, I.C.-H. All authors have read and agreed to the published version of the manuscript.

Funding: This research received no external funding.

Conflicts of Interest: The authors declare no conflict of interest.

\section{References}

1. Hernández-Mogollón, J.M.; Di-Clemente, E.; Folgado-Fernández, J.A.; Campón-Cerro, A.M. Olive oil tourism: State of art. Tour. Hosp. Manag. 2019, 25, 1-29. [CrossRef]

2. Pulido-Fernández, J.I.; Casado-Montilla, J.; Carrillo-Hidalgo, I. Introducing olive-oil tourism as a special interest tourism. Heliyon 2019, 5. [CrossRef] [PubMed]

3. Millán, M.G.; Agudo, E.; Morales, E. Análisis de la oferta y la demanda del oleoturismo en el sur de España: Un estudio de caso. Cuad. Desarro. Rural 2011, 8, 181-202.

4. Molina, V.; Quesada, J.M.; Ruiz, I. Potencial del oleoturismo como diversificación económica del sector cooperativo agrario: El caso español. Rev. Cienc. Soc. 2011, XVII, 533-541.

5. Millán-Vázquez, M.G.; Arjona-Fuentes, J.; Amador-Hidalgo, L. Olive oil tourism: Promoting rural development in Andalusia (Spain). Tour. Manag. Perspect. 2017, 21, 100-108. [CrossRef]

6. Cañero, P.; López-Guzmán, T.; Moral, S.; Orgaz, F. Análisis de la demanda del oleoturismo en Andalucía. Rev. Estud. Reg. 2015, 104, 133-149.

7. Weiler, B.; Hall, C.M. Special Interest Tourism; Bellhaven Press: London, UK, 1992.

8. Ávila, R. Introducción al concepto de sostenibilidad y turismo sostenible. In Turismo Sostenible; Ávila, R., Iniesta, A., Herrero, D., De Juan, J.M., Aguirre, G., Guereña, A., Morera, C., Beluche, G., Aguilar, P., Zambrano, D., et al., Eds.; IEPALA: Madrid, Spain, 2002; pp. 17-24.

9. Brotherton, B.; Himmetoğlu, B. Beyond destinations-Special interest tourism. Anatolia 1997, 8, 11-33. [CrossRef]

10. Torres, E. El sistema de actividades turísticas. In Estructura de Mercados Turísticos; Torres, E., Ed.; Universidad Oberta de Catalunya: Barcelona, Spain, 2006; pp. 15-75.

11. Agarwal, S.; Busby, G.; Huang, R. Special interest tourism: An introduction. In Special Interest Tourism; Agarwal, S., Graham, B., Rong, H., Eds.; CABI: London, UK, 2018; pp. 1-17.

12. López-Sánchez, Y.; Pulido-Fernández, J.I. Productos de turismo cultural. In Turismo Cultural; Pulido-Fernández, J.I., López-Sánchez, Y., de la Calle Vaquero, M., Eds.; Velasco-González. Síntesis: Madrid, Spain, 2013; pp. 171-202.

13. Trauer, B. Conceptualizing special interest tourism—Frameworks for analysis. Tour. Manag. 2006, 27, $183-200$. [CrossRef]

14. Soleimani, S.; Bruwer, J.; Gross, M.J.; Lee, R. Astro-tourism conceptualization as special-interest tourism (SIT) field: A phenomenological approach. Curr. Issues Tour. 2018, 22. [CrossRef]

15. Hall, C.M.; Weiler, B. What's special about special interest tourism. In Special Interest Tourism; Weiler, B., Hall, C.M., Eds.; Belhaven Press: London, UK, 1992; pp. 1-14.

16. de Salvo, P.; Hernández-Mogollón, J.M.; Di Clemente, E.; Calzati, V. Territory, tourism and local products. The extra virgin oil's enhancement and promotion: A benchmarking Italy-Spain. Tour. Hosp. Manag. 2013, 19, 23-34.

17. Čehić, A.; Mesić, Ž.; Oplanić, M. Requirements for development of olive tourism: The case of Croatia. Tour. Hosp. Manag. 2020, 26, 1-14. [CrossRef]

18. Hernández, J.M.; Folgado, J.A.; Campón, A.M. Oleoturismo en la Sierra de Gata y las Hurdes (Cáceres): Análisis de su potencial a través de un test de producto. Inter. J. Sci. Manag. Tour. 2016, 2, 333-354. 
19. Millán, M.G.; Arjona, J.; Amador, L. A new market segment for olive oil: Olive oil tourism in the South of Spain. Agric. Sci. 2014, 5, 179-185. [CrossRef]

20. Millán, M.G.; Morales, E.; Agudo, E. El oleoturismo como motor de desarrollo rural. La denominación de origen de Montoro-Adamuz. Mundo Agrar. 2010, 11, 1-27.

21. Morales-Fernández, E.; Lanquar, R.; Castro-Freire, M.S.; Trechera-Herreros, J.L. Una aproximación al perfil del oleoturista en las denominaciones de origen de Córdoba (España). Tour. Manag. Stud. 2015, 11, 31-38. [CrossRef]

22. Henderson, J.C. Food tourism reviewed. Br. Food J. 2009, 111, 317-326. [CrossRef]

23. Hall, C.M.; Sharples, L. The consumption of experiences or the experience of consumptions? An introduction to the tourism to taste. In Food Tourism around the World, 1st ed.; Hall, M., Sharples, L., Mitchel, R., Macionis, N., Cambourne, B., Eds.; Routledge: London, UK, 2004; pp. 1-24.

24. Carrillo-Hidalgo, I.; Casado-Montilla, J.; Pulido-Fernández, J.I. Características de la oferta de oleoturismo. Estructuración interna para operar en el mercado turístico. ESPACIOS 2019, 40, 15.

25. López-Guzmán, T.; Cañero, P.; Moral, S.; Orgaz-Agüera, F. An exploratory study of olive tourism consumers. Tour. Hosp. Manag. 2016, 22, 57-68. [CrossRef]

26. Millán, M.G.; Pablo-Romero, M.P.; Sánchez-Rivas, J. Oleotourism as a sustainable product: An analysis of its demand in the South of Spain (Andalusia). Sustainability 2018, 10, 101. [CrossRef]

27. Orgaz, F.; Moral, S.; López-Guzmán, T.; Cañero, P. Estudio de la demanda existente en torno al oleoturismo. El caso de Andalucía. Cuad. Tur. 2017, 39, 437-453. [CrossRef]

28. Millán, M.G.; Pérez, L.M. Comparación del perfil de enoturistas y oleoturistas en España. Un estudio de caso. Cuad. Desarr. Rural 2014, 11, 165-188. [CrossRef]

29. Vilar, J.; Pereira, J. La Olivicultura Internacional. Difusión Histórica, Análisis Estratégico Y Visión Descriptiva; Fundación Caja Rural de Jaén: Jaén, Spain, 2018.

30. International Olive Council (2019). World Olive Oil Figures. Available online: http://www.internationaloliveoil. org/estaticos/view/131-world-olive-oil-figures?lang=en_US (accessed on 15 July 2020).

31. Regional Department of Farming, Fisheries and Rural Development. 2019. Available online: https://www.juntadeandalucia.es/organismos/agriculturaganaderiapescaydesarrollosostenible/areas/ industrias-agroalimentarias/calidad-promocion/paginas/denominaciones-calidad-aceite-oliva.html (accessed on 15 July 2020).

32. Martínez, M. Caracterización de Aceites de Oliva Virgen Elaborados en Zonas Oleícolas de Extremadura; Universidad de Extremadura: Extremadura, Spain, 2016.

33. Survey of Crop Areas and Yields. Ministry of Farming, Fisheries and Food. 2019. Available online: http://www.mapama.gob.es/es/estadistica/temas/estadisticas-agrarias/agricultura/esyrce/ (accessed on 15 July 2020).

34. Spanish National Statistics Institute. Hotel Industry and Tourism. 2020. Available online: https://www.ine. es/dyngs/INEbase/en/categoria.htm?c=Estadistica_P\&cid=1254735570703 (accessed on 15 July 2020).

35. Campón-Cerro, A.M.; Folgado-Fernández, J.A.; Hernández-Mogollón, J.M. Rural destination development based on olive oil tourism: The impact of residents' community attachment and quality of life on their support for tourism development. Sustainability 2017, 9, 1624. [CrossRef]

36. Millán, M.G.; Amador, L.; Arjona, J.M. El oleoturismo: Una alternativa para preservar los paisajes del olivar y promover el desarrollo rural y regional de Andalucía (España). Rev. Geo. Norte Gd. 2015, 60, 195-214. [CrossRef]

37. Alonso, A.D.; Krajsic, V. The theory of planned behavior, micro-growers and diversification: An exploratory study. J. Enterprising Communities People Places Glob. Econ. 2015, 9, 94-113. [CrossRef]

38. Alonso, A.; Northcote, J. The development of olive tourism in Western Australia: A case study of an emerging tourism industry. Int. J. Tour. Res. 2010, 12, 696-708. [CrossRef]

39. Elias, S.; Barbero, A. Situación del oleoturismo y lineamientos para su desarrollo en la región del sudoeste bonaerense, Argentina. Revista Interamericana de Ambiente y Turismo 2017, 3, 91-104. [CrossRef] 
40. Arikan-Saltik, I. Initiative activities of olive oil tourism: A case from turkey. J. Acad. Soc. Sci. 2017, 5, 134-151. [CrossRef]

41. Arikan-Saltik, I.; Çeken, H. New trends in agrotourism: Olive oil tourism. J. Life Econ. 2018, 4, 89-102. [CrossRef]

42. Tkaczynski, A. Segmentation using two-step cluster analysis. In Segmentation in Social Marketing; Dietrich, T., Rundle-Thiele, S., Kubacki, K., Eds.; Springer: Singapore, 2017; pp. 109-125. 